\title{
Nonstrategic subjective threshold effects in phonemic masking
}

\author{
BENJAMIN XU and CHARLES A. PERFETTI \\ University of Pittsburgh, Pittsburgh, Pennsylvania
}

\begin{abstract}
Three backward-masking experiments demonstrated that the magnitude of the phonemic mask reduction effect (MRE) is a function of subjective threshold and that the magnitude is also independent of stimulus-based response strategies. In all three experiments, a target word (e.g., bake) was backward masked by a graphemically similar nonword (e.g., BAWK), a phonemically similar nonword (e.g., BAIK), or an unrelated control (e.g., CRUG). Experiments 1 and 2 had a low percentage (9\%) of trials with phonemic masks and differed only in baseline identification rate. Experiment 3 controlled baseline identification rate at below and above subjective threshold levels, with $9 \%$ phonemic trials. The results were that identification rates were higher with phonemic masks than with graphemic masks, irrespective of the low percentage of phonemic trials. However, the magnitude of the phonemic MRE became large only when the baseline identification rate was below subjective threshold. The pattern of the phonemic MRE was interpreted as a result of rapid automatic phonological activation, independent of stimulusbased processing strategies.
\end{abstract}

Over the last two decades, a number of studies using brief-stimulus-presentation and masked-stimuluspresentation paradigms have reported phonological effects in visual word identification (e.g., Lukatela \& Turvey, 1994a, 1994b; Naish, 1980; Perfetti \& Bell, 1991; Perfetti, Bell, \& Delaney, 1988; Perfetti \& Zhang, 1991; Van Orden, 1987; Van Orden, Johnston, \& Hale, 1988). These effects have been taken as major evidence for a rapid, automatic, and obligatory phonological process during lexical access. However, recently, several researchers have raised questions about these findings, particularly about the phonemic mask reduction effect (MRE) reported in studies using backward-masking paradigms (Brysbaert \& Praet, 1992; Verstaen, Humphreys, Olson, \& D'Ydewalle, 1995). For example, Brysbaert and Praet (1992) suggested that the phonemic MRE observed with these paradigms may be influenced by stimulus composition. They found that a phonemic MRE occurred when the list contained a high percentage (about $80 \%$ ) of homophones but not when the percentage of homophones was low (below 18\%). This result led Brysbaert and Praet to conclude that the phonemic MRE reported in previous studies might have been due to participants' strategic use of phonological information instead of an obligatory process of phonology.

The study reported in this paper was completed when the first author was at the University of Pittsburgh. The authors would like to thank Guy Van Orden and the two other reviewers for their critique and helpful comments on the manuscript. The authors are also grateful to Robert Lorch for his suggestions for the improvement of the manuscript and to Maria Walsh and Mara Georgi for their help in conducting the experiments. Correspondence should be addressed to B. Xu, National Institute of Neurological Disorders and Stroke, National Institutes of Health, 5N 250 Bldg. 10, Center Dr. MSC 140, Bethesda, MD 20892 (e-mail: benxu@codon.nih.gov).
To appreciate the implications of the strategy-control hypothesis, it is useful to consider briefly the studies that have been taken to demonstrate a nonstrategic phonological process as the source of the MRE. Naish (1980) found that when a target word (e.g., talk) was backward masked by either a nonword or a word, the identification of the word was enhanced by the mask if the mask (e.g., torck or torque) was homophonic to the target word. Under the same masking condition, a semantically related mask (e.g., speak) showed little facilitating effect on word identification. On the basis of these results, Naish suggested that the observed facilitating effect of masking "must be specifically phonological and probably occurs more centrally than the simple feature detecting level" (p. 66). Perfetti et al. (1988) further found that phonemic masking enhances word identification above and beyond graphemic masking. When a target word (e.g., bear) was backward masked by a pseudoword (e.g., BAIR, a phonemic mask) sharing all the phonemes of the target, participants identified significantly more target words than when a pseudoword mask (e.g., BOIR, a graphemic mask) contained the same number of letters but shared only a few phonemes with the target word. The phonemic mask substantially reduced the disruptive effect of a backward mask on target identification, more so than the graphemic mask. Since, under masking conditions, information about a stimulus is often partially activated, Perfetti et al. interpreted the phonemic MRE as due to the reinstatement of the partial phonological activation of the target by the mask. The observation of the phonemic MRE led Perfetti and his colleagues to conclude that word identification is influenced by rapid prelexical phonological processing, which is "never ... wholly delayed until some "moment of access' and never being omitted" (Perfetti et al., 1988, p. 68). This conclusion was further supported by evidence 
from a separate study conducted by Perfetti and Bell (1991) and other studies using visual backward-masking procedures (Lukatela \& Turvey, 1990, 1996).

Brysbaert and Praet (1992), however, challenged results from backward-masking studies. They argued that the phonemic MRE reported in Perfetti et al.'s (1988) study might have been due to a strategic effect associated with a large percentage (33\%) of phonemic masks. Brysbaert and Praet conducted several experiments in Dutch using similar backward-masking procedures only to observe contrasting results. They failed to find a phonemicmasking advantage when the phonemically masked trials made up $18 \%$ and $5.6 \%$ of the experimental trials. They did find an effect when the percentage of homophone trials was $77.8 \%$. Brysbaert and Praet argued that a large percentage of phonemic masks might have induced the otherwise optional phonological "incorporation" (i.e., mediation) in word identification-a process that led to the occurrence of a large phonemic MRE. Although Brysbaert and Praet did not exclude the possibility of prelexical phonological activation, they concluded that phonological information was not used automatically in lexical access, but only when the reader sensed its "appropriateness." On similar grounds, Verstaen et al. (1995) also questioned the nature of the phonemic MRE generated with backward-masking procedures. Using homophone words as targets in their experiments (Experiments 2-4), they did not find a phonemic MRE when the target words were all homophones nor when the experimental trials were preceded by a large number of homophone filler trials. On the basis of these results, Verstaen et al. also concluded that "phonemic effects in backward masking can be influenced by control strategies" (p. 352). Although no evidence in their data indicated the locus of control, Verstaen et al. argued that the phonemic MRE may be subject to the influence of processing strategies that may be located on either the "input control" (i.e., inhibit the activation of phonology) or the "output control" (i.e., "inhibit the output from phonological representations to the decision processes"; Verstaen et al., 1995, p. 352).

The results of these studies have raised a question about the nature of the phonological effects observed with backward-masking procedures. If the phonemic MRE was a result of only the phonological information evoked by the readers' sense of "appropriateness," then previous conclusions regarding phonological mediation based on backward-masking results would appear to be incorrect.

There are, however, additional considerations having to do with the functional stimulus display that also bear on the interpretation of effects in brief-exposure-masking paradigms. By "functional stimulus display," as opposed to such nominal parameters as presentation duration and SOA, we mean the opportunity for processing afforded by the stimulus conditions. This opportunity is affected by a variety of objective factors: the luminance contrast of the display, the actual target duration, subject characteristics (e.g., reading skill), and target characteristics. We can summarily refer to the ability of a subject to achieve above-chance response accuracy afforded by the functional stimulus display as the subjective threshold. Qualitatively different effects by above- and below-subjective-threshold presentation of stimulus have been reported by a number of researchers (e.g., Carr, McCauley, Sperber, \& Parmelee, 1982; Cheesman \& Merikle,1986; Merikle \& Joordens, 1993). Cheesman and Merikle (1986) reported that, in a Stroop priming task, naming latencies of the targets were affected by predictive strategies only when the prime duration was set at above-subjective-threshold level (i.e., at least $50 \%$ correct identification of the primes). Therefore, in our three experiments, we adopted a $50 \%$ identification rate in the baseline condition as a reference point for distinguishing below versus above subjective threshold. It is important to point out that the subjective threshold as defined here may be affected by any of the objective factors listed above, including the luminance contrast of the display and the target duration. While most studies report nominal duration times, very few report other display measures that would affect subjective threshold.

Subjective threshold, as an indicator of functional stimulus display, in fact is a critical component of briefpresentation paradigms. For example, early research on masking effects showed that the level of luminance contrast is important in determining the outcomes from rapid visual presentation (Turvey, 1973). Turvey demonstrated that when presentation time was held constant, the masking effect varied as the target luminance changed. Because backward masking employs rapid visual presentation, its sensitivity to rapid and automatic effects, as opposed to strategic effects, may depend on the subjective threshold. The part of the phonemic-masking effect that is automatic may require display and subject characteristics that produce below-subjective-threshold processing. The part of the effect that is subject to strategic control may be most visible when processing is above threshold.

Because studies, including Perfetti et al. (1988; Perfetti \& Bell, 1991) and Brysbaert and Praet (1992), have generally reported only durations or stimulus onset asynchronies (SOAs) and not other parameters that bear on subjective thresholds, comparisons of results across laboratories must be carried out with caution. It is possible that failures to observe a robust phonemic MRE in both Brysbaert and Praet's study and Verstaen et al.'s (1995) study were partially due to the difference in the stimulusviewing opportunity between these studies and those by Perfetti and his colleagues (Perfetti \& Bell, 1991; Perfetti et al., 1988). Evidence for this possibility comes from the high identification rates reported by Brysbaert and Praet. In their study, the baseline rates (i.e., the rate for words followed by control masks) in experiments 2 and 3 exceeded $50 \%$, suggesting that participants had above-threshold viewing opportunity. Likewise, three of four of Verstaen et al.'s experiments had above $50 \%$ baseline identification rates. However, the baseline identification rates (near or below $30 \%$ ) in Perfetti and Bell (1991) and Perfetti et al. (1988) indicated that their participants had below-subjective-threshold stimulus-view- 
ing opportunity when significant phonemic MRE was observed (see Berent \& Perfetti, 1995, for other criticisms of Brysbaert \& Praet's, 1992, study).

There are a number of ways to approach the subjective threshold question. One could vary stimulus energy and duration in combination, for example. However, the most straightforward way is simply to control for luminance and set duration parameters that allow a restricted range of subjective threshold, individualized for each subject. Thus, our approach in Experiment 1 was to measure the baseline identification rate of each subject in a thresholdsetting procedure, using that measure as a setting for the experimental trials. ${ }^{1}$

\section{EXPERIMENT 1}

The purpose of Experiment 1 was to test Brysbaert and Praet's (1992) suggestion that the phonemic MRE reported in Perfetti et al. (1988) was induced by a high proportion of phonemic masks. We adopted the stimuli used in Perfetti et al. but reduced the number of phonemicmasking trials to about $9 \%$ of the experimental trials, similar to the percentage used in Brysbaert and Praet's study. A failure to find a phonemic MRE would add to the null results that would be consistent with a strategy factor. However, finding a phonemic MRE effect would demonstrate that such an effect could be found with lowpercentage phonemic masks under some circumstances. In order to ensure comparability with the experiments reported in Perfetti et al. (1988), materials and experimental display methods were identical. Specifically, stimuli were presented by tachistoscopic shutter rather than computer screen.

A premise of Experiment 1 was that the baseline identification rates were an appropriate index of subjective threshold and that simple manipulations of stimulus display parameters were not appropriate. Because the display characteristics of a CRT screen are very different from those of our tachistoscopic lab, we subsequently replicated Experiment 1 on a computer screen. Other than the display method, the only difference between Experiment 1 and the replication was a slight increase of the number of phonemic-masking trials. The percentage of phonemicmasking trials was $18 \%$ in the replication-a figure intermediate to the $9 \%$ of Experiment 1 and the $33 \%$ of Perfetti et al. (1988). The $18 \%$ was achieved by reducing the number of filler trials used in Experiment 1 . We reasoned that, on one interpretation of the strategy hypothesis of Brysbaert and Praet (1992), one might expect an increase in the phonemic MRE as the percentage of phonemicmasking trials increased even when the baseline identification rate was controlled to match that of Experiment 1. Except for the slight increase of the percentage of the phonemic-masking trials, identical materials, procedures, and measures for the baseline identification rate were adopted in the replication. The results of the replication were nearly identical to those of Experiment 1 in terms of both the magnitude of the phonemic MRE (6.7\% vs. $6.6 \%)$ and the overall baseline identification rates $(22.4 \%$ vs. $26 \%$ ). There was little increase of the phonemic MRE as a result of doubling the phonemic-masking trials. Since the patterns of the results and the materials and procedures used in the two experiments were identical, we combined the results and report them together as a single experiment.

\section{Method}

Participants. Sixty University of Pittsburgh undergraduate students participated in the experiment. Forty-five participated to fulfill a course requirement, and 15 were paid volunteers.

Materials and Apparatus. All the target stimuli (with modification) including 30 words and three types of masks ( 30 each) were originally used in Perfetti et al.'s (1988) study. Each target word (e.g., bake) was paired with the three types of pseudoword masks: a phonemic mask (a pseudohomophone, e.g., BAIK), a graphemic mask (e.g., BAWK), and a control (e.g., CRUB). Pseudohomophones and graphemic masks were equated in the number of letters they shared with the target, but the pseudohomophone masks shared additional phonemes with the target. Control masks had neither letters nor phonemes in common with the target. In addition to the $30 \mathrm{tar}$ get words, there were 80 filler words, which were always paired with a control mask.

Three Kodak slide projectors mounted with tachistoscopic shutters were used for stimulus presentation. The tachistoscopic shutters were interfaced with a PC computer for controlling presentation times. All stimuli were displayed in black color and projected on a $9 \times 4 \mathrm{~cm}$ white frosted screen. The size of the stimuli were about $11 \times 0.5 \mathrm{~cm}$ on the screen, forming a horizontal visual angle of approximately $2^{\circ}$. (In the replication study, stimuli were presented on a 14-in. noninterlaced VGA monitor interfaced with a Gateway 2000 computer with the Courier PS font type in blue color and dark background.)

Procedure. Before the experiment began, the participants received a threshold test. Each participant saw 20 warm-up trials followed by 30 test trials. Each trial contained a word presentation followed by a control mask and then by a pattern mask consisting of a row of uppercase Xs $(\mathrm{XXXXX)}$, which also served as the fixation point. Target words were presented in lowercase, and masks were presented in uppercase. The interstimulus interval (ISI) between the target and the pseudoword mask and the ISI between the pseudoword mask and the pattern mask were both zero. The control mask was displayed for $30 \mathrm{msec}$; the pattern mask was displayed until the participant pressed a button to begin the next trial. The display duration for the target word, however, varied in the following fashion. For the 20 warm-up trials, designed to ensure some success in identification, the durations descended in order across four values: 100 , 85,65 , and then $55 \mathrm{msec}$, each of which had 5 trials. In the following 30 test trials, designed to determine an approximate range of subjective threshold, there were three durations in a descending order: 55,45 , and $35 \mathrm{msec}$, with 10 trials per duration. ${ }^{2}$ The participants' task was to orally report the word they identified after each trial. They were given oral feedback (i.e., "correct" or "wrong") after each response. The participant's identification threshold was defined as the last word-presentation duration in which the participant could successfully identify at least 3 words $(30 \%)$ out of the 10 trials. If this criterion was not achieved for even the longest duration of the test trials $(55 \mathrm{msec})$, the participant's threshold was set at $65 \mathrm{msec}$. No participant in the experiment had a threshold lower than $45 \mathrm{msec}$. 
The experimental session followed the threshold test. In the experimental session, each participant saw 110 word-mask pairs, of which 30 were the critical trials and 80 were fillers. For the critical trials, each participant saw 10 target words paired with phonemic masks, 10 with graphemic masks, and 10 with control masks. The target word-mask pairs were counterbalanced using a Latin square design, such that each participant saw a target word only once in the experiment. The word-pseudohomophone pairs (phonemic trials) formed about $9 \%$ of the total number of trials in the experimental session. Before the first trial, the participants saw the pattern mask at the center of the screen. The participants were instructed to press a button to start a trial. Each stimulus sequence was similar to that in the threshold test: A word followed by a pseudoword mask and then by the pattern mask. The display duration of the target word was set according to each participant's threshold. As in the threshold test, the duration for the three types of masks was always $30 \mathrm{msec}$, and the pattern mask stayed on until the participant pressed the button for the next trial. The distribution of target and filler trials was constant across participants, with 10 initial filler trials followed by a continuous alternation of a single target trial and two filler trials, ending with 10 filler trials. The participants immediately wrote the word they saw after each trial. They were encouraged to guess if they were not sure about what they saw, but they were told that it was OK to leave the response blank if they had no guess to make about the word. No feedback was provided during the experimental session.

The statistical analyses for all the experiments were conducted on correct identification responses of the critical trials only. All results (Experiments 1-3) were significant at $p<.05$, unless otherwise indicated.

\section{Results}

The results of Experiment 1 showed that, on average, the participants correctly identified more words in the phonemic-mask (pseudohomophone) condition (50\%) than in the graphemic-mask (43.3\%) and control mask $(24 \%)$ conditions. An analysis of variance (ANOVA) showed a significant main effect of mask condition both by participants $(F 1)$ and by items $(F 2)[F 1(2,118)=$ 51.41, $\left.M S_{\mathrm{e}}=212.8 ; F 2(2,58)=21, M S_{\mathrm{e}}=12.2\right]$. Post hoc (Tukey) comparisons confirmed that all three means differed significantly from each other. The critical values for comparisons were 6.3 (by participants) and 2.17 (by items) when the familywise $\alpha$ was set at a level of .05 .

The threshold-setting procedure resulted in a mean target exposure duration of $58 \mathrm{msec}$ when stimuli were projected on the white frosted screen through tachistoscopic shutters. The average target duration was $16 \mathrm{msec}$ when the stimuli were presented on a computer screen. However, according to the subjective threshold hypothesis, what are most relevant are the base rates of identification, which can and did vary across participants. Among the 60 participants, these baseline rates (based on control masks) were less than $50 \%$ for 51 participants. However, the rate was $50 \%$ for 8 participants, and it was $60 \%$ for 1 participant. Of the 8 participants who had a $50 \%$ baseline identification rate, only 2 identified more words with the phonemic mask than with the graphemic mask. Four showed no phonemic MRE, identifying an equal number of words with phonemic and graphemic masks, and 2 had the trend reversed. The participant whose baseline identification rate was $60 \%$ also identified more words in the graphemic-mask condition $(80 \%)$ than in the phonemic condition (60\%). Among the 51 participants who had less than $50 \%$ baseline identification, 31 identified more words with phonemic masks than with graphemic masks, 13 participants identified more words with graphemic masks, and 7 had no difference between the two mask conditions.

\section{Discussion}

Despite the fact that phonemic masks constituted only about $9 \%-18 \%$ of the trials, there was a $6.7 \%$ advantage of phonemic masks over graphemic masks, a result consistent with the findings reported in Perfetti and Bell (1991) and Perfetti et al. (1988). The results did not confirm Brysbaert and Praet's (1992) claim that the advantage of phonemic masks over graphemic masks was a result of a higher percentage of phonemic-mask trials. Also, consistent with previous findings, both the phonemic masks and the graphemic masks produced significantly larger MREs than did the baseline control, about $26 \%$ and $19.3 \%$, respectively, which were also similar to the results of Perfetti et al.'s study. In addition, the level of subjective threshold indexed by the baseline identification rate $(24 \%)$ for the control condition was comparable to that reported in Perfetti et al., suggesting that, in both studies, a phonemic MRE arose in low-subjective-threshold conditions. Finally, it is consistent with the subjective threshold hypothesis that the phonemic MRE was more likely to be observed in the participants who identified fewer than $50 \%$ of the words paired with the control masks.

In addition, despite the fact that the mean exposure duration was much shorter in the replication $(16 \mathrm{msec})$ than in Experiment $1(58 \mathrm{msec})$, the results were identi$\mathrm{cal}$ in that a phonemic MRE was found in both. This suggests that the base rate, which was the same in the two cases, may be more important than duration when different participants and viewing conditions are involved. Also, inconsistent with a simple interpretation of the strategy hypothesis, doubling the phonemic percentage in our replication did not increase the magnitude of the phonemic MRE.

The simple conclusion is that at least some conditions, including those of Experiment 1, may produce a phonemic MRE with a low percentage of phonemic trials. However, is it further possible to understand why null results may also be obtained with low-percentage conditions as in Brysbaert and Praet (1992)?

\section{EXPERIMENT 2}

Failures to observe a phonemic MRE may be partly linked to display conditions that are above participants' subjective thresholds. The possibility that Brysbaert and Praet's (1992, Experiments 2 and 3) and Verstaen et al.'s (1995) failure to find a phonemic MRE might have resulted from such conditions is suggested by the above $50 \%$ identification rates in their baseline (control) conditions. If so, then arranging conditions that favor above- 
subjective-threshold processing may diminish or eliminate the phonemic MRE. This is what we tried to do in Experiment 2 by increasing stimulus-viewing opportunity.

But why should viewing opportunity matter for these masking effects? An extended viewing opportunity should allow more complete central processing of the word than should a reduced viewing opportunity. Consequently, on a greater number of trials, the activation of a word representation should increase on the basis of the visual input alone. For these trials, lexical activation is above threshold, and "complete" rather than partial, and the perceptual identification itself cannot benefit from the reinstatement of the mask. Instead, strong lexical activation based on the word input only may attenuate or eliminate the phonemic MRE, which has been interpreted as the result of reinstating information to the partial results of an interrupted identification process (Perfetti et al., 1988). If this reasoning is correct, then when stimulus-viewing opportunity is set at above-subjective-threshold level, phonemic MRE beyond graphemic MRE should be weaker or disappear. In addition, we should expect to see a general increase in identification rates across all masking conditions.

\section{Method}

Participants. Thirty undergraduates from the University of Pittsburgh participated in the experiment in fulfilling a partial course requirement. None of the participants had participated in similar experiments.

Materials and Apparatus. The experiment was also conducted on a tachistoscope with the same equipment and settings as in Experiment 1. Materials were identical to those used in Experiment 1.

Procedure. The procedure and instructions were also identical to those in Experiment 1. The participants were given a threshold test prior to the experimental session with word-control mask pairs. The only departure from Experiment 1 was the threshold setting used for the experimental trials, which was set at the last exposure duration in the descending series at which the participant successfully identified 5 or 6 words $(50 \%-60 \%)$ out of 10 trials. This threshold criterion was set to approximate the identification rate (above 50\%) of the control condition reported in Brysbaert and Praet (1992).

\section{Results}

The results of Experiment 2 showed that, on average, the participants identified more words in the phonemic $(81 \%)$ and graphemic $(78 \%)$ conditions than in the control condition $(60.3 \%)$. A one-way ANOVA showed a significant main effect of mask type both by participants and by items $\left[F 1(2,58)=16.63, M S_{\mathrm{e}}=225 ; F 2(2,58)=16.13\right.$, $\left.M S_{\mathrm{e}}=2.4\right]$. Post hoc (Tukey) comparisons revealed that the mean of the baseline condition (i.e., the control masking condition) differed significantly from those of the phonemic- and graphemic-masking conditions. However, the difference $(3 \%)$ between the phonemic and graphemic conditions was not statistically significant either by participants or by items. The Tukey critical values for comparisons were 9.3 by participants and 0.96 by items when the familywise $\alpha$ was set at a level of .05 .

The threshold-setting procedure resulted in a mean target exposure duration of $62 \mathrm{msec}$. In terms of individ- ual participants, 9 out of the 30 had a baseline identification rate below 50\%. Among these 9 subthreshold participants, 6 identified more words with the phonemic mask than with the graphemic mask, 2 showed no difference between the two mask conditions, and only 1 performed better in the graphemic condition than in the phonemic condition. In contrast, for the 16 participants who had above $50 \%$ baseline identification rate, only 6 identified more words with the phonemic mask than with the graphemic mask. Of the 5 participants who achieved 50\% baseline rate, only 2 showed a phonemic MRE over and above the graphemic MRE.

\section{Discussion}

The results of Experiment 2 are consistent with the hypothesis that conditions that favor high baseline identification rates can decrease the phonemic MRE while increasing identification rates in all conditions. For all three conditions, the participants of Experiment 2 identified more words than did those of Experiment 1. However, the phonemic MRE was reduced in magnitude to $3 \%$ and was not statistically reliable. Furthermore, the participants who actually performed at below $50 \%$ threshold showed phonemic effects in 6 of 9 cases, compared with 6 of 16 among those who performed above $50 \%$. These data almost mirror those of Experiment 1, which found a phonemic-graphemic difference for two thirds of the participants below the $50 \%$ threshold. Thus, each experiment was largely successful in arranging conditions that produce below-threshold (Experiment 1) and abovethreshold (Experiment 2) processing, with the majority of participants in each experiment identifying words at the rate suggested by the threshold-setting procedure. However, in the experimental trials, a number of participants performed at rates different from those of their test trials, especially in Experiment 2. For those participants, the phonemic effects were in line with the expectation of the subjective threshold hypothesis. In effect, the nonsignificant phonemic MRE of Experiment 2 was entirely due to the participants who were above subjective threshold. Thus, although the two experiments employed the same low percentage of phonemic masks, they differed in the extent to which they produced a phonemic MRE. The difference is consistent with the hypothesis that baseline identification rate or the subjective threshold affects the emergence of the phonemic MRE.

Although the first two experiments together demonstrate the plausibility of the subjective threshold hypothesis, a more direct test would be a manipulation of base rates within a single experiment. This was done in Experiment 3.

\section{EXPERIMENT 3}

If our analysis is correct, we should be able to observe the appearance and disappearance of the phonemic MRE as a function of subjective threshold. Furthermore, the emergence of the effect should occur even in strategy- 
discouraging conditions, as shown in Experiment 1. Thus, Experiment 3 maintained a low percentage $(9 \%)$ of phonemic-mask trials while varying subjective thresholds across $10 \%, 40 \%, 70 \%$, and $90 \%$ baseline identification rates. We reasoned that this broad range of baseline rates would capture a highly general picture of the rise and fall of the phonemic MRE. It also emphasizes the fact that while individual word activation thresholds may be conceived as "below" or "above" (i.e., dichotomous around $50 \%$ ), for some purposes, a threshold-setting procedure is strictly a statistical device influencing the probability that a given word-identification process has been completed. Because Experiments 1 and 2 had already provided data for the baseline rates ranging between $20 \%-30 \%$ and $50 \%-60 \%$, we did not include rates at these ranges in Experiment 3 .

\section{Method}

Participants. Eighty-four undergraduate students from the subject pool of the University of Pittsburgh participated in the experiment as a partial requirement for a psychology class.

Materials and Apparatus. All the stimuli including the filler trials were the same as those used in Experiments 1 and 2, except for the three phonemic and graphemic masks that differed by more than one letter from their paired words. These masks were modified so that the two types of masks all had the same number of letters as their target words and only one letter off position. The apparatus was identical to that used in Experiments 1 and 2.

Procedure. The threshold test procedure was identical to that adopted in Experiments 1 and 2, except that the threshold criteria were set to satisfy the four baseline identification rates $(10 \%, 40 \%$, $70 \%$, and $90 \%$ ), which then defined four experimental conditions. The participants were assigned to the conditions in a sequence according to the order of their arrival. Other procedures were identical to those of Experiments 1 and 2. In addition, at the end of the experiment, we explicitly asked the participants whether or not they noticed the presentation of the mask in each trial. No participants in any of the four conditions reported being aware of the presentation of the mask.

Data analysis. All the planned comparisons of means using participants as a random factor were carried out with two-sample $t$ tests (two-tailed). The strong one-directional effects in previous research, including Experiment 1, suggests that specific planned comparisons are appropriate. Similar comparisons with items as a random factor were performed with paired $t$ tests for each baseline condition, because each target word was paired with all three types of masks. However, two-sample $t$ tests were also used for comparisons of the magnitude of the MRE between baseline conditions.

\section{Results}

General. Figure 1 shows a trend indicating that, relative to the graphemic-mask condition, phonemic masks facilitated target identification when the baseline identification rates were below $50 \%$ subjective threshold level. The observed facilitation was largest when the baseline rate was controlled at about $40 \%$ in the experiment. A mixed two-factor ANOVA, using participants as a random factor, with baseline rate (i.e., $10 \%, 40 \%, 70 \%$, and $90 \%$ ) as a between-subjects factor and with mask type (pseudohomophone, grapheme, and control) as a within-subjects factor, showed significant main effects of baseline rate
$\left[F(3,80)=105.41, M S_{\mathrm{e}}=588\right]$ and mask type $[F(2,160)=$ 21.2, $\left.M S_{\mathrm{e}}=152.7\right]$. These main effects were also significant by item analysis $\left[F(3,116)=131, M S_{\mathrm{c}}=3.32\right.$, and $F(2,232)=18, M S_{\mathrm{e}}=1.3$, respectively]. In addition to the main effects, there was also a significant interaction between baseline rate and mask type both by participants and by items $\left[F 1(6,160)=2.64, M S_{\mathrm{e}}=152.7\right.$; $\left.F 2(6,232)=2.82, M S_{\mathrm{e}}=1.3\right]$. Simple comparisons revealed that the interaction was partly due to a large difference $(9.1 \%)$ between the phonemic and graphemic masks in the $40 \%$ baseline condition relative to the other three baseline conditions.

Figure 2 provides a general picture of the magnitude of the phonemic MRE for the four baseline (i.e., subjective threshold) conditions. The magnitude of the phonemic MRE (i.e., the difference in identification rates between the phonemic and graphemic conditions) was substantially larger when the baseline identification rate was controlled at subthreshold level $(3.3 \%$ for the $10 \%$ condition, and $9.1 \%$ for the $40 \%$ condition) than when it was above the subjective threshold level $(-1.9$ for the $70 \%$ condition, and -0.5 for the $90 \%$ condition). Furthermore, the magnitude of the phonemic MRE was $5.8 \%$ larger in the $40 \%$ condition than in the $10 \%$ condition. Planned comparisons showed that the magnitude of the phonemic MRE was significantly larger in the $40 \%$ condition than in the $70 \%$ condition by participants $[t(40)=2.1]$ and marginal by items $[t(58)=1.83, p<.08]$. The difference between the $40 \%$ condition and the $90 \%$ condition was marginal by participants $[t(40)=1.82, p<.08]$ but significant by items $[t(58)=2.1]$. The difference $(5.8 \%)$ between the $40 \%$ and $10 \%$ baseline conditions was not statistically significant $(t<1)$. In summary, as seen in Figure 2, phonemicmask effects were seen in low-baseline conditions and disappeared at high-baseline conditions.

The graphemic MRE showed a somewhat different course. The magnitude of the graphemic MRE (the difference in identification rates between the graphemicmask and control mask conditions) was actually largest in the $10 \%$ condition $(15.2 \%)$, decreasing with increasing baseline rates $(10.5 \%, 6.2 \%, 5.2 \%)$. Planned comparisons revealed that the graphemic MRE was significantly stronger in the $10 \%$ condition than in the $70 \%$ condition $[t(40)=2.2$, and $t(58)=2.1$, respectively $]$ and the $90 \%$ condition $[t(40)=2.1$, and $t(58)=2$, respectively]. However, the difference between the $10 \%$ and $40 \%$ conditions was not statistically reliable $(t<1)$. The $40 \%$ condition also did not differ significantly from the other three conditions.

By baseline (i.e., subjective threshold) condition. For the $10 \%$ condition, an ANOVA showed a significant main effect of mask type both by participants and by items $\left[F 1(2,40)=12.2, M S_{\mathrm{e}}=168.7 ; F 2(2,58)=10.86, M S_{\mathrm{e}}=\right.$ 1.6]. The participants identified more words in the phonemic $(23.8 \%)$ and graphemic $(20.5 \%)$ conditions than in the control condition (5.2\%). Planned comparisons revealed that the differences between the phonemic and con- 


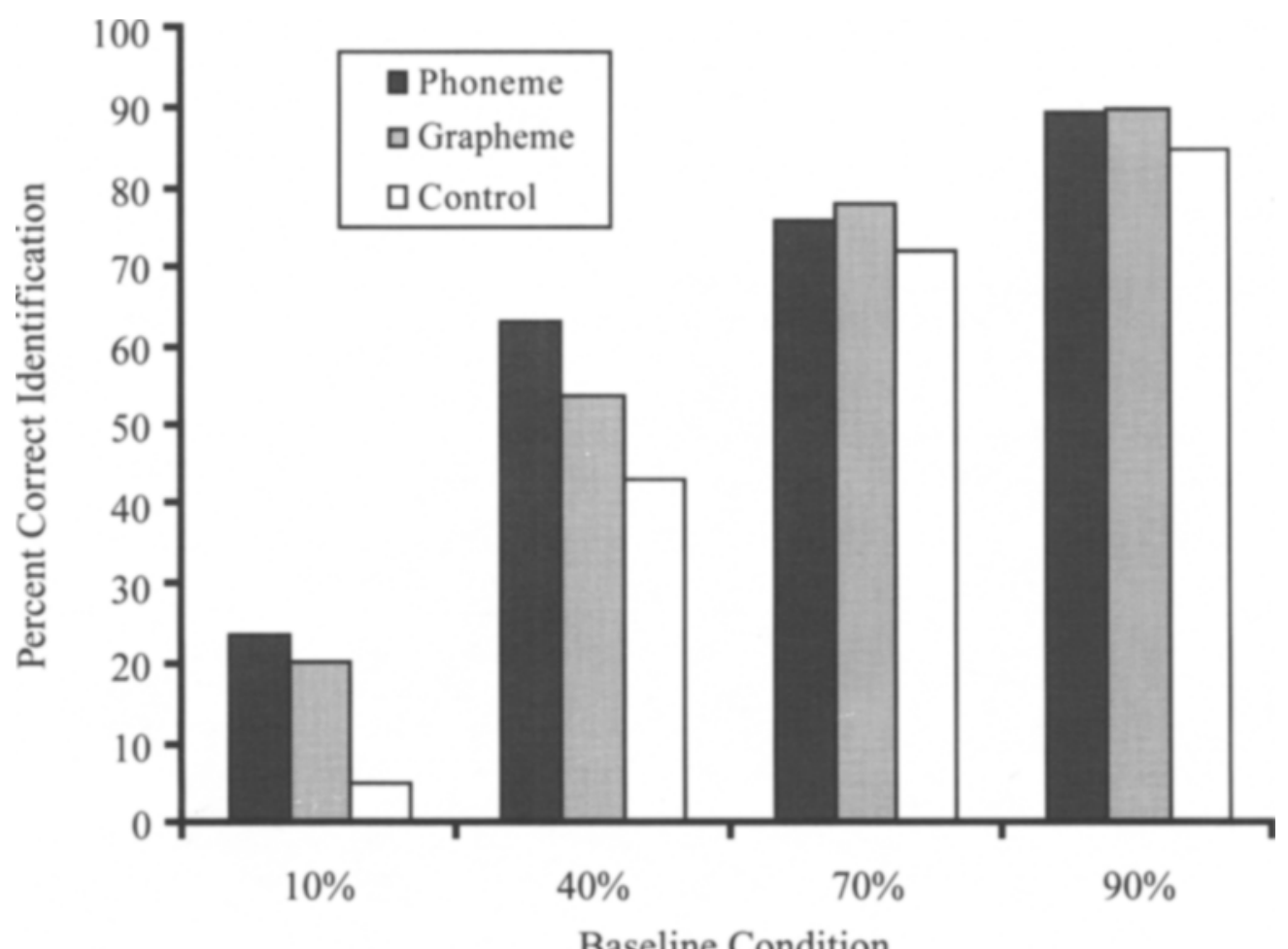

Figure 1. The percentage of correct identification of target words with three types of masks in four baseline conditions in Experiment 3.

trol conditions as well as between the graphemic and control conditions were significant both by participants $[t(40)=3.8$, and $t(40)=3$, respectively $]$ and by items $[t(29)=4.6$, and $t(29)=4.5$, respectively]. However, the difference $(3.3 \%)$ between the phonemic-mask and graphemic-mask conditions did not reach statistical significance $(t<1)$.

For the $40 \%$ condition, the ANOVA also showed a significant main effect of mask type both by participants and by items $\left[F 1(2,40)=8.48, M S_{\mathrm{e}}=236.4 ; F 2(2,58)=7.62\right.$, $\left.M S_{\mathrm{e}}=1.8\right]$. Planned comparisons indicated that the effect was partially due to the difference $(9.1 \%)$ between the phonemic and graphemic conditions $(62.9 \%$ and $53.8 \%$, respectively) which was significant by item analysis $[t(29)=1.85]$ although marginal by participants $[t(40)=$ $1.67, p=.10]$. The participants also identified significantly more words in the phonemic condition than in the control condition $(43.3 \%)$ both by participants and by items $[t(40)=3.6$, and $t(29)=4.1$, respectively $]$. For the graphemic condition, the difference was significant by item analysis $[t(29)=1.98]$ but marginal by participants $[t(40)=1.89, p<.07]$.

As in Experiments 1 and 2, the performance of individual participants was relevant. In the $40 \%$ condition, among the 21 participants, 3 had $50 \%$ baseline (control mask) identification rates, 7 had rates in excess of $50 \%$, and 11 had rates under $50 \%$. Of these 11 low-rate participants, 6 identified more words paired with the phonemic mask $(66.6 \%)$ than with the graphemic mask (38.3\%). However, of the 7 participants with above- $50 \%$ baseline identification rate, 5 showed no difference between the phonemicmask and graphemic-mask conditions.

For both the $70 \%$ condition and the $90 \%$ condition, an ANOVA showed no significant main effect of mask type either by participant or by item analyses. In the $70 \%$ condition, the participants, on average, identified slightly more words in the graphemic condition $(78 \%)$ than in the phonemic condition $(76 \%)$ and the control $(71 \%)$. This trend maintained in the $90 \%$ condition-that is, the graphemic mask led to a slight increase of correct responses $(90 \%)$ in comparison with the phonemic mask $(89.5 \%)$ and the control (84\%) (see Figure 1).

\section{Discussion}

The results of Experiment 3 were consistent with our prediction that the size of the phonemic MRE would be influenced by subjective threshold, as indexed by the baseline identification rate. The participants tended to identify more words paired with phonemic masks than with graphemic masks when the display was set to produce sub- 


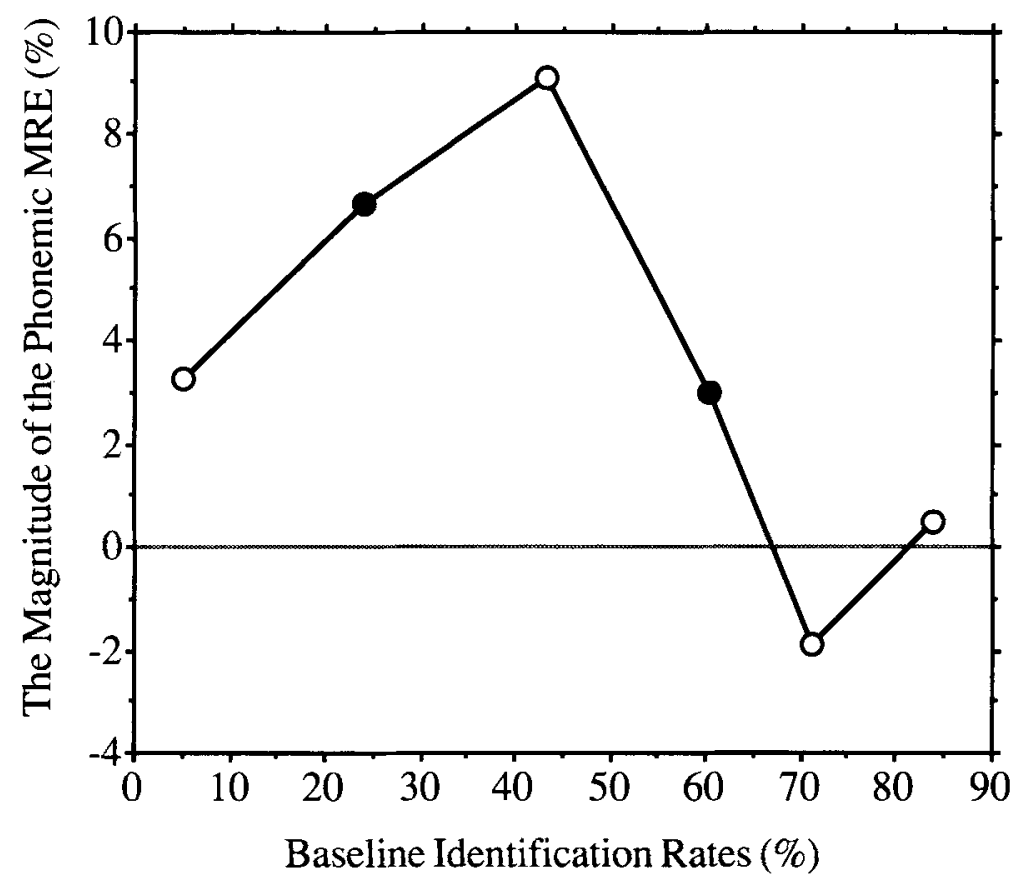

Figure 2. The magnitude of the phonemic MRE effect as a function of the baseline identification rate (i.e., subjective threshold) plotted across Experiments 1-3. The baseline identification rates plotted here are the actual observed percentages of the correct responses in the control conditions. The darkened circles represent data from Experiments 1 and 2.

threshold performance (10\% and $40 \%$ baselines). Indeed, the phonemic MRE disappeared beyond $70 \%$.

Important is the fact that, across all conditions, the percentage of phonemic masks was low at $9 \%$. The finding of phonemic MRE under sub-50\% conditions thus replicates the results of Experiment 1. This increases confidence that the phonemic MRE does not depend on the presence of a high percentage of phonemic MREs among the trials. Furthermore, the disappearance of the phonemic MRE at high baseline rates replicates the result of Experiment 2. This increases confidence that subjective threshold, not proportionality, controls the phonemic MRE.

Unlike the phonemic MRE, however, the magnitude of the graphemic MRE decreased approximately linearly from $10 \%$ to $90 \%$ baseline identification rate. Thus, graphemic information was activated very rapidly and increased with viewing opportunity. Beyond this description, the interpretation of the difference between graphemic and phonemic masks is a matter of conjecture. One interpretation is simply that graphemic information is activated first and the effects of phonology rapidly converge. This interpretation would be consistent with other results that show slightly earlier graphemic effects relative to phonemic effects in masked priming (Davis \& Forster, 1994; Ferrand \& Grainger, 1993, 1994; Forster, Davis, Schoknecht, \& Carter, 1987; Perfetti \& Bell, 1991). Another possibility is that the early graphemic effects partly reflect consonant phonology, whereas the later phonological ef- fects add mainly vowel phonology, as suggested by the two-cycles model (Berent \& Perfetti, 1995). However, consonant-vowel phonology was not controlled in the experiment, so this hypothesis is untested in the present data. For either the graphemes-first or the two-cycles model, an additional assumption is needed to explain the divergence of graphemic and phonemic MREs with higher baseline identification rates-namely, that the phonemic effect is sensitive to a threshold-related activation level, whereas the graphemic effect is not. At above $50 \%$ threshold levels, the graphemic effects may persist through a spelling verification process (Van Orden, 1987) rather than through prelexical information. Thus, viewing reinstated letters (in the mask) that had been in the target may add verified information that is already the result of processing of graphemic-phonological prelexical information. By contrast, the phonemic MRE, which is defined as an increment to a graphemic effect that itself may be partly phonological, is reflecting primarily prelexical phonological activation. This interpretation is, of course, the original explanation for the effect (Perfetti et al., 1988).

\section{GENERAL DISCUSSION}

These experiments demonstrate that the phonemic MRE can be observed with a low percentage of phonemically masked trials. Thus, although it may be of inter- 
est to discover whether the effect can be observed at even lower percentages, the suggestion that the effect depends on strategies evoked by the occurrence of frequent homophone trials is not tenable. This is not to say that strategic effects cannot be observed. The conclusion is rather that there is a phonemic effect that arises from early nonstrategic processes that operate in word identification.

The experiments further implicate a very different factor that can control the emergence of the phonemic factor: functional display characteristics that reflect individual subjective threshold. In Experiment 1, we observed a phonemic effect under subthreshold differences. In Experiment 2 , we found only nonsignificant effects with above-threshold differences. Furthermore, in both experiments, the baseline rates within the experimental trials predicted the appearance of the effect for individual participants. Experiment 3 again demonstrated these effects across a range of baseline conditions.

In fact, the pattern of the phonemic MRE remained unchanged even when the magnitude of the effect was plotted across all three experiments as a function of the baseline identification rate (see Figure 2). These results contrast the pattern of the graphemic MRE, which was still observed at above subjective threshold (Experiments 2 and 3). Thus, across the experiments, the phonemic MRE was fairly robust even with a small percentage of phonemically masked trials.

We cannot determine why Brysbaert and Praet (1992) and Verstaen et al. (1995) failed to observe the phonemic MRE in their studies. However, it seems relevant that, on average, participants in the two studies had above-threshold baseline identification rates in almost all of their experiments that failed to produce a significant phonemic MRE. Our results suggest that higher base rates favor graphemic effects while discouraging incremental phonemic effects. ${ }^{3}$

On the more general question of whether masking effects are subject to processing strategies, the answer is not a simple yes or no but depends on an analysis of the elements of strategic controls and the experimental conditions that affect these elements. When "strategic control" is defined as "the goal-directed, purposeful use of resources" (Moray, 1975, p. 302), volitional elements are emphasized. These would operate only by identification of stimulus features and the intention to control responses to them (also see Newell, 1994; Underwood, 1978). Strategic control of phonological information in masking requires at least three conditions. First, participants must be aware of the phonological relationship between the target and the mask. Second, they must know that suppressing or using this relationship can help or hinder identification accuracy. Third, they must be able to bring about selective use or suppression within the experimental trials. If these conditions are not satisfied, it is difficult to argue that the phonemic MRE can be a result of strategic control. Parsimony suggests that the effect should be attributed to nonstrategic (automatic) processes that operate on target or mask (Lukatela \& Turvey, 1990, 1996; Perfetti \& Bell, 1991; Perfetti et al., 1988).

Of course, even within this volitional definition of strategy, procedural manipulations can exert influence even when the participant lacks complete knowledge of the relevant task variable (Underwood, 1978). For example, simply telling participants that, in each trial, a word is masked by a briefly presented nonword letter string may cause them to move their identification criteria toward the formal stimulus and away from the interpreted cognitive event. Similarly, increasing task complexity can lead to processes that are resource-limited rather than data-limited (Norman \& Bobrow, 1975). Data-limited processes may be crucial for detecting rapid and automatic phonological processes (Ziegler \& Jacobs, 1995; Ziegler, Van Orden, \& Jacobs, 1997).

However, strategic control has another relevant element in work on word identification: an unconscious modulation or tuning of processing routes during word recognition (Baluch \& Besner, 1991; Brysbaert \& Praet, 1992; Monsell, Matthews, \& Miller, 1992; Paap \& Noel, 1991; Verstaen et al., 1995). In this sense of strategy, the effect of strategic control is largely a result of automatic rather than volitional processes. We can assume that strategy effects of the volitional type and the automatic type are a part of many experimental situations. Masking should be no exception. However, the opportunity for the volitional type should be restricted to conditions that promote explicit knowledge of materials, feedback, and the ability to exercise control. The automatic type is more relevant within the parameters of most masking experiments; however, even this kind of strategy control requires feedback to tune performance, as exemplified in various models of word recognition (e.g., Grainger \& Jacobs, 1996; Grossberg \& Stone, 1986; Jacobs \& Grainger, 1992; McClelland \& Rumelhart, 1981; Rumelhart \& McClelland, 1982). However, the functional stimulus displays in many experiments, including the present set, may not provide feedback, which can occur only if the participant has actually made an above-threshold identification.

Thus, although the tuning sense of strategy is the most applicable to the masking situation, it remains to be explained how the phonemic MRE might be subject to databased (e.g., the proportion of phonemically masked trials) processing strategies when participants were unaware of the target-mask relationship and given no feedback on performance (also see Forster et al., 1987; Grainger \& Ferrand, 1994; Merikle \& Joordens, 1993; Underwood, 1975).

In conclusion, the phonemic MRE can be obtained with a low percentage of phonemically masked trials. Thus, the phonemic MRE cannot simply be attributed to processing strategies induced by list composition. Equally important, the magnitude of the phonemic MRE is sensitive to subjective threshold, as indexed by the baseline identification rate. Two implications follow from this: Methodologically, brief exposure studies with masks need to take subjective thresholds into account by control of 
functional stimulus displays. Theoretically, at least one locus of the phonemic effect in masking would lie in the partial (prelexical) results of word identification, because conditions that produce low levels of identification should be most sensitive to these processes.

\section{REFERENCES}

BALUCH, B., \& BESNER, D. (1991). Visual word recognition: Evidence for strategic control of lexical and nonlexical routines in oral reading. Journal of Experimental Psychology: Learning Memory \& Cognition, $17,644-652$

Berent, I., \& Perfetti, C. A. (1995). A Rose is a REEZ: The twocycles model of phonology assembly in reading English. Psychological Review, 102, 146-184.

Brysbaert, M., \& Praet, C. (1992). Reading isolated words: No evidence for automatic incorporation of the phonetic code. Psychological Research, 54, 91-102.

Carr, T. H., McCauley, C., Sperber, R. D., \& Parmelee, C. M. (1982). Words, pictures, and priming: On semantic activation, conscious identification, and the automaticity of information processing. Journal of Experimental Psychology: Human Perception \& Performance, 8, 757-777.

Cheesman, J., \& Merikle, P. M. (1986). Distinguishing conscious from unconscious perceptual processes. Canadian Journal of Psychology, 40, 343-367.

DAVIS, C., \& FORSTER, K. I. (1994). Masked orthographic priming: The effect of prime-target legibility. Quarterly Journal of Experimental Psychology, 47A, 673-697.

FERRAND, L., \& GRAINGER, J. (1993). The time course of orthographic and phonological code activation in the early phases of visual word recognition. Bulletin of the Psychonomic Society, 31, 119-122.

FERRAND, L.. \& GRAINGER, J. (1994). Effects of orthography are independent of phonology in masked form priming. Quarterly Journal of Experimental Psychology, 47A, 365-382.

Fisk, A. D., \& SCHNEIDER, W. (1984). Memory as a function of attention, level of processing, and automatization. Journal of Experimental Psychology: Learning, Memory, \& Cognition, 10, 181-197.

ForSTER, K. I., Davis, C., SCHOKNeChT, C., \& CARTER, R. (1987). Masked priming with graphemically related forms: Repetition or partial activation? Quarterly Journal of Experimental Psychology, 39A, 211-251.

Grainger, J., \& Ferrand, L. (1994). Phonology and orthography in visual word recognition: Effects of masked homophone primes. Journal of Memory \& Language, 33, 218-233.

Grainger, J., \& JACOBS, A. M. (1996). Orthographic processing in visual word recognition: A multiple read-out model. Psychological Review, 103, 518-565.

GrossberG, S., \& Stone, G. O. (1986). Neural dynamics of word recognition and recall: Priming, learning, and resonance. Psychological Review, 93, 46-74.

JACOBS, A. M., \& GraingER, J. (1992). Testing a semistochastic variant of the interactive activation model in different word recognition experiments. Journal of Experimental Psychology: Human Perception \& Performance, 18, 1174-1188.

Lukatela, G., \& Turvey, M. T. (1990). Automatic and pre-lexical computation of phonology in visual word identification. European Journal of Cognitive Psychology, 2, 325-343.

Lukatela, G., \& Turvey, M. T. (1994a). Visual lexical access is initially phonological: 1 . Evidence from associative priming by words, homophones, and pseudohomophones. Journal of Experimental Psychology: General, 123, 107-128.

Lukatela, G., \& Turvey, M. T. (1994b). Visual lexical access is initially phonological: 2 . Evidence from phonological priming by homophones and pseudohomophones. Journal of Experimental Psychology: General, 123, 331-353.

Lukatela, G., \& Turvey, M. T. (1996). Inhibition of naming by rhyming primes. Perception \& Psychophysics, 58, 823-835.
MCClelland, J. L., \& Rumelhart, D. E. (1981). An interactive activation model of context effects in letter perception: Part 1 . An account of basic findings. Psychological Review, 88, 375-407.

MerikLe, P. M., \& JoORDENS, S. (1993, May). Measuring unconscious influences. Paper presented at the 25th Carnegie Symposium on Cognition: Scientific Approaches to the Question of Consciousness, Pittsburgh.

Monsell, S., Matrhews, G. H., \& Miller, D. C. (1992). Repetition of lexicalization across languages: A further test of the locus of priming. Quarterly Journal of Experimental Psychology, 44A, 763-783.

MORAY, N. (1975). The strategic control of information processing. In R. L. Solso (Ed.), Information processing and cognition: The Loyola symposium (pp. 301-328). Hillsdale, NJ: Erlbaum.

NAISH, P. (1980). The effects of graphemic and phonemic similarity between targets and masks in a backward visual masking paradigm. Quarterly Journal of Experimental Psychology, 32, 57-68.

NewEll, A. (1994). Unified theories of cognition. Cambridge, MA: Harvard University Press.

Norman, D. A., \& Bobrow, D. G. (1975). On data-limited and resource-limited processes. Cognitive Psychology, 7, 44-64.

PAaP, K. R., \& NoEL, R. W. (1991). Dual-route models of print to sound: Still a good horse race. Psychological Research, 13, 13-24.

Perfetti, C. A., \& Bell, L. (1991). Phonemic activation during the first $40 \mathrm{msec}$ of word identification: Evidence from backward masking and priming. Journal of Memory \& Language, 30, 473-485.

Perfetti, C. A., Bell, L., \& Delaney, S. (1988). Automatic phonetic activation in silent word reading: Evidence from backward masking. Journal of Memory \& Language, 27, 59-70.

Perfetti, C. A., \& Zhang, S. (1991). Phonological processes in reading Chinese words. Journal of Experimental Psychology: Learning, Memory, \& Cognition, 17, 633-643.

RumelhaRT, D. E., \& McClelland, J. L. (1982). An interactive activation model of context effects in letter perception: Part 2 . The contextual enhancement effect and some tests and extensions of the model. Psychological Review, 89, 60-94.

SCHNEIDER, W., \& FISK, A. D. (1982). Concurrent automatic and controlled visual search: Can processing occur without resource cost? Journal of Experimental Psychology: Learning, Memory, \& Cognition, 8, 261-278.

TURVEY, M. T. (1973). On peripheral and central processes in vision: Inferences from an information-processing analysis of masking with patterned stimuli. Psychological Review, 80, 1-52.

UNDERWOOD, G. (1975). Attention and the perception of duration during encoding and retrieval. Perception, 4, 291-296.

UNDERWOOD, G. (1978). Attentional selectivity and behavioral control. In G. Underwood (Ed.), Strategies of information processing (pp. 235 266). London: Academic Press.

VAN ORDEN, G. C. (1987). A ROWS is a ROSE: Spelling, sound, and reading. Memory \& Cognition, 15, 181-198.

Van Orden, G. C., Johnston, J. C., \& Hale, B. L. (1988). Word identification in reading proceeds from spelling to sound to meaning. Journal of Experimental Psychology: Learning, Memory, \& Cognition, 14, 371-385.

Verstaen, A., Humphreys, G. W., Olson, A., \& D'Ydewalle, G. (1995). Are phonemic effects in backward masking evidence for automatic prelexical phonemic activation in visual word recognition? Journal of Memory \& Language, 34, 335-356.

Ziegler, J. C., \& JaCoBs, A. M. (1995). Phonological information provides early sources of constraint in the processing of letter strings. Journal of Memory \& Language, 34, 567-593.

Ziegler, J. C., VAN ORden, G. C., \& JaCobs, A. M. (1997), Phonology can help or hurt perception. Journal of Experimental Psychology: Human Perception \& Performance, 23, 845-860.

\section{NOTES}

1. Baseline identification rates are better indexes for stimulus-viewing opportunity than stimulus presentation duration alone. This is because, 
all things being equal, any successful identification of a word paired with a control mask that bears no resemblance to the word can only be a result of the activation of the word stimulus itself and not the mask or the two combined. Another reason that using baseline identification rates may be a better way of controlling stimulus-viewing opportunity across laboratories lies in the fact that participants differ in their perceptual threshold. Even though luminance values were available, setting the presentation time and luminance constant across laboratories or experiment may still result in significant difference in performance because of subject difference. However, using baseline identification rates as an index for stimulus-viewing opportunity minimizes such difference. Again, since luminance values are unavailable in the studies under question, the only way to determine the relative stimulus-viewing opportunity across laboratories is to compare baseline identification rates among these studies.

2. In the replication, the same threshold testing procedure was used as in Experiment 1. However, the target presentation duration had to be set slightly shorter in replication than in Experiment 1 . Shortening presentation duration made it possible for the threshold procedure to provide equivalent measures for achieving the baseline identification rate at about 30\% (i.e., below subjective threshold) for each participant, as in Experiment 1. The difference in presentation duration might have been partly due to the differences in the variation of luminance caused by the characteristics of the displaying methods (i.e., tachistoscopic projectors vs. CRT screen) and the environment (i.e., tachistoscope lab vs. the computer lab).

3. It is also possible that other procedural aspects of the studies might have reduced the chances of finding a phonemic MRE in these studies. In both studies, participants were instructed to identify and write down both the mask and the target (in this order). Such a procedure may well work against implicit processing or partial activation effects by creating attention demands greater than in single-target report (Fisk \& Schneider, 1984; Schneider \& Fisk, 1982). This procedure may also have encouraged participants to search for relationships between the target and the mask, reducing automatic phonological effects in masking. However, despite these problems, Verstaen et al.'s (1995) data actually revealed a tendency for more homophone errors (i.e., producing the homophonic alternative of the target word) in the phonemic-mask condition than in the graphemic condition. This seems to require an explanation that assumes a unique contribution of the phonemic mask, although a clear explanation of this is difficult for the procedural reasons mentioned above.
APPENDIX Stimuli for All Three Experiments

\begin{tabular}{|c|c|c|c|}
\hline Target & Pseudohomophone & Grapheme & Control \\
\hline$\overline{\mathrm{BAKE}}$ & BAIK & BAWK & CRUB \\
\hline BITE & BIGHT & BISHT & DROK \\
\hline BLAME & BLAIM & BLARM & $\mathrm{CROSH}$ \\
\hline BOAT & BOTE & BOTS & CIRE \\
\hline BRAIN & BRANE & BRANT & FLEST \\
\hline CHAIR & CHARE & CHARK & SLUGE \\
\hline CLAIM & KLAME & KLAMB & ROUNT \\
\hline CODE & KOAD & KOID & SNAL \\
\hline CRATE & KRAIT & KRAST & SKOND \\
\hline DOLL & DAWL & DEWL & GAIK \\
\hline DOOR & DORE & DODE & NADE \\
\hline DROP & DRAWP & DREAP & FLIN \\
\hline FAME & FAIM & FAUM & CRON \\
\hline FILE & FIAL & FIEL & BORT \\
\hline FOOD & FUDE & FIDE & YINK \\
\hline GLUE & GLOO & GLAM & TRIN \\
\hline HOME & HOAM & HOSH & TING \\
\hline KITE & KIGHT & KIRST & MANG \\
\hline MAKE & MAYK & MANK & COND \\
\hline NOON & NUNE & NANE & LERB \\
\hline PAIN & PAYN & PARN & SHEG \\
\hline RAID & RADE & RADS & KETS \\
\hline ROLL & ROAL & RELL & CAFT \\
\hline ROOM & RUME & RIME & SINT \\
\hline SOCK & SAWK & SASK & FERM \\
\hline STEAK & STAIK & STAUK & CHOIT \\
\hline TRAIN & TRANE & TRANK & GLOUM \\
\hline TROOP & TRUPE & TRAPE & MALSH \\
\hline WAIT & WATE & WATS & PRES \\
\hline WEAR & WAIR & WIER & MOND \\
\hline
\end{tabular}

(Manuscript received March 3, 1997; revision accepted for publication December 16, 1997.) 